\title{
Jogos Inteligentes Tangíveis como Instrumento de Mensuração Cognitiva
}

\author{
Érica J. S. Scheffel ${ }^{1,2}$, Claudia L. R. Motta ${ }^{1,2}$, Carla Verônica M. Marques ${ }^{1}$ \\ ${ }^{1}$ Instituto Tércio Pacitti de Aplicações e Pesquisas Computacionais - Universidade Federal \\ do Rio de Janeiro (UFRJ) \\ ${ }^{2}$ Programa de Pós-Graduação em Informática - Universidade Federal do Rio de Janeiro
} (UFRJ)

Av. Athos da Silveira Ramos, 274 - 21.941-916 - Rio de Janeiro - RJ - Brasil

\{ericascheffel, claudiam, carlaveronica\}@nce.ufrj.br

\begin{abstract}
The objective of this article is to present a innovative proposal of a robotic instrument capable of providing a study about how some of the cognitive processes that form intelligence, such as Planning, Attention, Successive and Simultaneous Processing [Luria 1966], manifest themselves in the new experience described by Piaget as Assimilation Process and later Accommodation process [Piaget 1976], in order to verify, in a playful, three-dimensional and tangible form if possible failures in these processes can be minimized to improve the problemsolving capacity of school-age children.
\end{abstract}

Resumo. O objetivo deste artigo é apresentar uma proposta de instrumento robótico e inovador capaz de oportunizar um estudo sobre como alguns dos processos cognitivos formadores da inteligência como Planejamento, Atenção, Processamento Sucessivo e Simultâneo [Luria 1966] se manifestam no primeiro contato com uma nova experiência, descrita por Piaget como Assimilação e, por conseguinte, Acomodação [Piaget 1976], com o intuito de verificar, de forma lúdica, tridimensional e tangivel, se possiveis falhas nestes processos podem ser minimizadas para melhoria na capacidade de resolução de problemas das crianças em idade escolar.

\section{Introdução}

A preocupação com o déficit na aprendizagem dos brasileiros vem sendo manifestada por autores, pesquisadores e profissionais da educação desde o século passado e consiste na necessária adaptação da escola à realidade de cada época na qual a sociedade se encontra.

[...] o sistema educativo, em vigor numa época determinada, é fruto e reflexo da organização do trabalho da sociedade a que serve. Quando este se modifica, a escola, isto é, aquele aparelhamento a que incumbe o preparo adaptativo da massa maior dos membros da comunhão, não pode fugir à fatalidade de transformar-se [Mennucci 1934, p.26]. 
Apesar dos atuais avanços tecnológicos nas mais variáveis áreas de trabalho, a maioria das instituições educacionais fornece um ensino tradicional que estimula a obtenção de mérito através da memorização e da padronização dos resultados desejáveis, descartando as aptidões dos indivíduos que não se encaixam nestes, gerando a uniformização das pessoas que passam a se comportar de forma competitiva e não colaborativa como deveria ser para a saúde da sociedade. Este formato de educação propicia o desperdício das aptidões individuais, ou seja, o desuso das áreas de força de cada um [Marques 2017].

Além disso, os estudos do psicólogo e Professor Emérito da UFRJ Franco Lo Presti Seminério mostraram que as crianças que se desenvolvem em um meio social com menos recursos e sem acesso às experiências necessárias para sua formação cognitiva se tornam adultos com menor capacidade intelectual e este é um problema, não apenas educacional, mas social [Seminério 1984].

Desta forma, a preocupação com a aprendizagem dos brasileiros, principalmente quando se trata das crianças menos favorecidas socialmente, pode estar aliada aos novos instrumentos capazes de possibilitar a detecção de falhas existentes nos processos cognitivos com o intuito de que sejam reparadas de uma maneira lúdica e espontânea. A atual tecnologia viabiliza esta ferramenta, conforme já demonstrado na proposta dos Games Inteligentes, os quais são programados com inteligência artificial para observar e habilitar funções cognitivas de alta complexidade a partir da observação de suas reações diante da busca de soluções para os desafios propostos [Marques 2017]. Por fim, essa necessidade de construção de artefatos que promovam estudos sobre a formação epistêmica foi manifestada há mais de trinta anos pela cientista cognitiva Barbel Inhelder, cuja pesquisa foi desenvolvida, por décadas, ao lado de Jean Piaget:

Seria muito audacioso esperar que o cognitivismo construtivista pudesse, simultaneamente, oferecer uma orientação de pensamento e de pesquisa para as futuras construções de "máquinas de arquitetura psicogenética" e, também, um conhecimento cada vez mais aprofundado dos processos de direção, de regulação e de avaliação que sustentam a trajetória das descobertas na criança [Inhelder et. al. 1996, p.298]?

\section{Fundamentação Teórica}

Nessa seção serão apresentadas diferentes teorias referentes à formação cognitiva, mas que se complementam de forma essencial para a concepção deste trabalho.

\subsection{A Teoria PASS de Luria}

A Teoria da Inteligência conhecida como Teoria PASS (Planejamento, Atenção, Processamento Sucessivo e Processamento Simultâneo) foi extraída dos estudos do médico e psicólogo soviético especialista em psicologia do desenvolvimento Alexander Luria (1966), posteriormente aprofundada por Das, Naglieri e Kirby em 1994, cuja pesquisa, baseada em análises de neuroimagem e estudos clínicos de indivíduos com lesões cerebrais, mostrou que o cérebro é composto de sistemas funcionais interdependentes, porém isolados. Além da subdivisão cerebral e suas funcionalidades interdependentes, os estudos de Luria pressupõem que a inteligência está consolidada em quatro processos cognitivos os quais se ancoram cada um em sua região definida:

- Planejamento: refere-se ao processo cuja atividade foi identificada extensamente no lobo frontal, no qual se desenvolvem funções executivas cognitivas responsáveis 
VIII Congresso Brasileiro de Informática na Educação (CBIE 2019)

Anais do XXX Simpósio Brasileiro de Informática na Educação (SBIE 2019)

pelo controle e organização do comportamento, assim como a seleção e/ou construção de estratégias para resolução de problemas e o monitoramento do desempenho das estratégias aplicadas.

- Atenção: refere-se ao processo responsável pela manutenção dos níveis de alerta a fim de que o foco seja mantido nos estímulos de maior importância na resolução do problema, ignorando demais distrações. Durante esse processo, foram identificadas atividades em uma combinação que abrange o lobo frontal e partes inferiores do córtex, apesar de que os lobos parietais também se envolveram em alguns momentos de atenção.

- Processamento Sucessivo: responsável pela decodificação, transformação e retenção de informações para organização de itens separados em uma série, ou seja, são estímulos organizados em uma ordem sequencial. Nesse processo, atividades foram amplamente identificadas nos lobos frontal-temporais.

- Processamento Simultâneo: esse processo, cuja atividade cerebral acontece amplamente nos lobos occipital e parietal, também é responsável pela decodificação, transformação e retenção de informações, porém envolve a capacidade necessária para que os estímulos separados sejam integrados em um todo coeso e interrelacionado. Um simples exemplo disso é a identificação de duas imagens com figuras geométricas sobrepostas, sendo a primeira um círculo dentro de um quadrado e a segunda um quadrado dentro de um círculo.

\subsection{A Equilibração das Estruturas Cognitivas de Jean Piaget}

O estudo do epistemólogo suíço Jean Piaget (1976) apresenta a formação do conhecimento como produto de um processo central de equilibração que ocorre mentalmente nos sujeitos quando há experimentação de algo novo. Estes ciclos epistêmicos estão relacionados aos dois processos fundamentais para o equilíbrio cognitivo: Assimilação e Acomodação. $\mathrm{O}$ processo de Assimilação é a absorção de um elemento exterior, seja um objeto, situação ou qualquer conteúdo novo, por um esquema conceitual ou sensório motor existente no sujeito. Acomodação é o surgimento da necessidade de se considerar as peculiaridades do novo elemento exterior assimilado, transformando-o em um esquema conceitual ou sensório motor existente no indivíduo ou originando um novo esquema, modificando o conhecimento prévio existente. Sendo assim, o processo de Acomodação está sempre condicionado ao processo da Assimilação, porém, para que de fato aconteça é necessária uma atividade, ou seja, um certo esforço do sujeito, caso contrário o ser humano poderia assimilar todo o universo sem se enriquecer em compreensão [Piaget 1978].

\subsection{A Abordagem Psicomotora de Vitor da Fonseca}

Vitor da Fonseca desenvolveu a Bateria Psicomotora (BPM), cujo conjunto de situações ou tarefas visa analisar dinamicamente o perfil psicomotor da criança em concordância com a organização funcional do cérebro proposta por Luria (1966). Segundo Fonseca (2012) o psiquiatra Henri Wallon provavelmente foi o pioneiro da Psicomotricidade no campo científico o qual considerou o movimento como o primeiro instrumento do psiquismo [Wallon 1925 apud Fonseca 2012, p.13].

Dentre os fatores analisados na BPM, o que mais contribuiu para esse trabalho foi o estudo da Praxia Fina por tratar de funções como a coordenação dinâmica manual e velocidade com precisão. Estes quesitos foram utilizados no Jogo Inteligente Tangível como 
VIII Congresso Brasileiro de Informática na Educação (CBIE 2019)

Anais do XXX Simpósio Brasileiro de Informática na Educação (SBIE 2019)

marcadores da intencionalidade observada considerando-se o tônus muscular, ou seja, o estado involuntário de alerta e contração que se encontram os músculos em repouso, os quais podem ser mensurados na velocidade de algumas ações seguidas de instantes de preensão estática e reflexiva ou devido a sua troca vertiginosa após a mesma situação descrita. Ambas as situações podem revelar o estado de tensão que apresenta o músculo em repouso, permitindo o início da contração para uma rápida ação após o impulso dos centros nervosos. "O tônus muscular é o alicerce das atividades práticas" [Le Boulch 1992 apud OLIVEIRA 2001, p. 27].

\subsection{Os Games Inteligentes de Marques}

Os Games Inteligentes são jogos programados com inteligência artificial capazes de observar e habilitar funções cognitivas de alta complexidade através do trato lúdico, porém direto, com o computador [Marques 2017]. Sua construção envolve um processo constituído de quatro etapas fundamentais: Modelo Dimensional, Processo Criativo, Projeto Interacional e Desenvolvimento Conceitual [Marques 2005]. Um exemplo de Game Inteligente é o Jogo EICA que investiga a transitividade cognitiva entre diferentes áreas do conhecimento, como as áreas de linguagem, ciências e matemática.

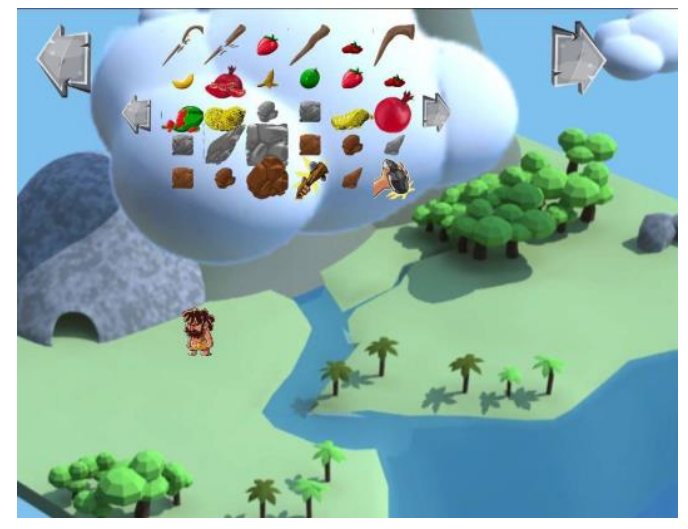

Figura 1. Jogo EICA [Marques 2017, p.70]

Neste artigo, a proposta apresentada utilizou a modelagem computacional desenvolvida para a construção de um Game Inteligente, porém adaptada à atual tecnologia disponível no ramo da robótica, pois dessa forma o artefato físico, equipado com sensores e microcontroladores, se torna capaz de promover a coleta de dados originados a partir de sua manipulação espontânea. O propósito desta coleta de dados é viabilizar o alinhamento destes às relevantes abordagens teóricas neurocognitivas, evidenciando assim, o reconhecimento de padrões não observáveis no processo de aprendizagem e resolução de problemas para transformá-los em dados registráveis, passíveis de análise e interferências. O resultado disso foi um jogo estrutural robótico-cognitivo munido de crivos, os quais analisam fatores eliciados do contato com o experimento, extraídos de conceitos abordados nas teorias supracitadas, mensurando assim, os níveis de Planejamento, Atenção, Processamento Sucessivo e Simultâneo que possam ocorrer durante o processo de Assimilação, para que sejam comparados com os níveis mensurados durante o processo de Acomodação. 


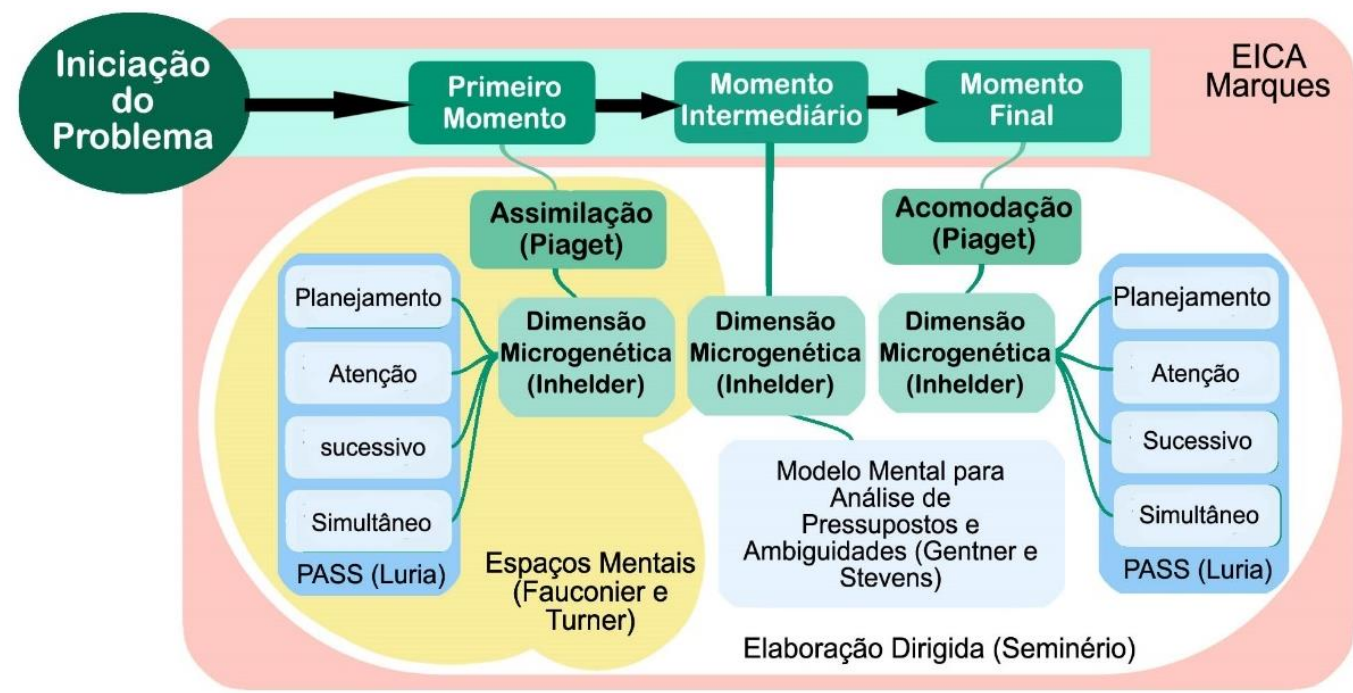

Figura 2. Relação entre as Teorias

\section{Trabalhos Correlatos}

Não foram encontrados, na literatura, propostas semelhantes à apresentada neste trabalho, onde o jogo computadorizado é composto de aparatos físicos, equipados com sensores e microcontroladores capazes de promover a coleta de dados para análise cognitiva mediante sua manipulação pelo usuário. O que existe, conforme já apresentado, é a metodologia para construção dos Games Inteligentes [Marques 2015] cuja implementação da robótica é algo totalmente inovador.

À parte das experimentações de nível cognitivo, o que há de correlação com este trabalho são os jogos tecnológicos tangíveis produzidos para entretenimento. Estes jogos tecnológicos são considerados tangíveis porque possibilitam interações palpáveis, onde os usuários atuam movimentando componentes físicos equipados com sensores $\mathrm{e}$ microcontroladores, a fim de permitir uma interação usuário-máquina. Um exemplo é o Reactable, um instrumento musical eletrônico com uma interface de usuário tangível, desenvolvido na Universidade Pompeu Fabra, Barcelona. Foi concebido em 2003 por Sergi Jordà, Günter Geiger, Martin Kaltenbrunner e Marcos Alonso, porém só foi apresentado ao público no ano de 2005, em um concerto na International Computer Music Conference de Barcelona.

Recentemente, Gluz et. al. (2018) apresentaram uma proposta de educação inclusiva para integração sensorial no ensino de Ciências por meio de um ambiente virtual tangível. Os autores consideram que uma ferramenta de ensino inovadora capaz de integrar a tecnologia tangível com a realidade virtual tem uma perspectiva inclusiva para os alunos com déficits na comunicação. Porém esta abordagem auxilia na transmissão de conteúdos escolares, cujo foco não é similar ao da proposta do Hash $3 D$.

\section{Jogo Inteligente Tangível (JIT): Hash 3D}

Como proposta de modelo estrutural robótico-cognitivo para criação de um Jogo Inteligente Tangível (JIT) foi desenvolvido o Hash $3 D$, cujas regras podem ser facilmente inferidas por se tratar de uma versão mais elaborada de um dos jogos mais antigos e praticados por pessoas de todas as idades e de todos os lugares do mundo: o Jogo da Velha. 


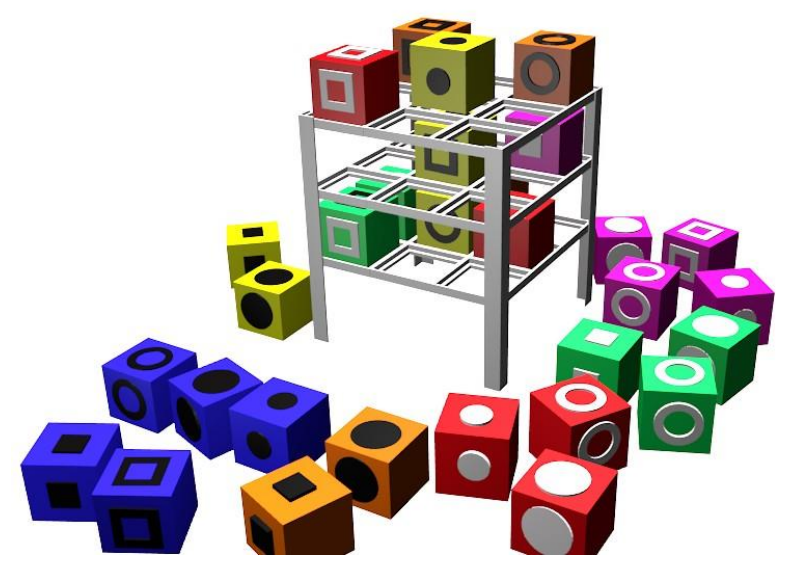

Figura 3. Imagem computadorizada do Hash 3D

O jogo tem como objetivo a formação sequencial, em linha reta e em qualquer direção possível, utilizando três elementos da mesma cor ou mesmo símbolo. Para isso, cada jogador dispõe de quinze peças, sendo cinco delas de cada da cor e com cinco tipos de símbolos diferentes, cada símbolo em uma das cores. Dessa forma, cada jogador possui cinco peças para formar sequências baseadas nas cores e apenas três para formar sequências baseadas nos símbolos. Cada jogador só pode formar sequências com suas próprias peças, as quais são identificadas pela cor dos símbolos: preto ou branco. Os jogadores se revezam e quando alguma sequência for completada corretamente, será disparado um sinal sonoro. Serão realizadas cinco partidas e as regras do jogo não são repassadas aos jogadores para que a primeira partida seja uma evidência do processo de Assimilação e a quinta e última, do processo de Acomodação.

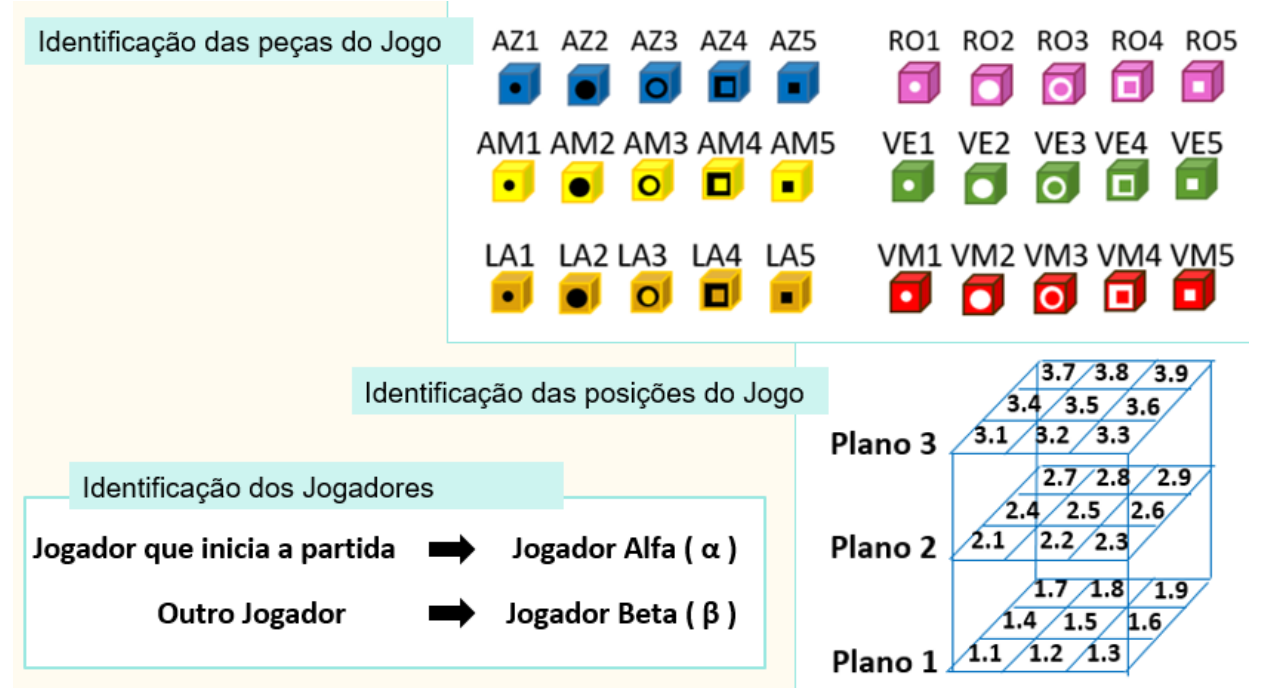

Figura 4. Identificação das peças, casas do tabuleiro 3D e jogadores

\subsection{O Modelo Robótico Cognitivo}

Com enfoque na dimensão microgenética, a construção do modelo dimensional proposto nessa pesquisa, a qual deu origem ao JIT, iniciou-se com a elaboração de um modelo mental que visa analisar a forma com que os indivíduos lidam com pressupostos (no sentido de que seja antecipado um possível resultado perante suas ideias de resolução) e também analisar 
VIII Congresso Brasileiro de Informática na Educação (CBIE 2019)

Anais do XXX Simpósio Brasileiro de Informática na Educação (SBIE 2019)

como esses lidam com as ambiguidades (no sentido de que sejam previstos mais de um resultado) quando estão diante da resolução de um problema, com intuito de evitar momentos de hesitação inesperada, assim como intensificar as possibilidades de decisões mais assertivas.

Não obstante analisar, apenas, se os indivíduos atuam inconscientemente com pressupostos e ambiguidades na resolução de problemas, o JIT foi concebido a partir da elaboração de crivos, ou seja, conjuntos de critérios neuropsicopedagógicos que definem as regras e as decisões por trás das funções do design do jogo [Marques 2017], os quais se concretizarão por meio da manipulação das peças desse artefato equipado com microcontroladores e com transmissores. Sendo assim, cada crivo foi especificado contemplando as possíveis ações e suas respectivas abordagens teóricas, como por exemplo, se o objetivo do jogo é formar sequências de três símbolos ou cores iguais, quando um jogador posiciona a segunda peça de uma sequência e o adversário aloca uma peça que impossibilite a conclusão da sequência alheia, a este será atribuído um ponto de Atenção, uma vez que, segundo Luria (1966), a Atenção se refere ao processo responsável pela manutenção dos níveis de alerta com o objetivo de que o foco seja mantido nas decisões mais relevantes.

Quadro 1: Descrição do Modelo Dimensional

\begin{tabular}{|c|c|}
\hline \multicolumn{2}{|r|}{ Definição das ações que pontuam cada ação específica } \\
\hline \multicolumn{2}{|r|}{ Dimensão Ontogenética } \\
\hline Assimilação & $\begin{array}{l}\text { - As ações da primeira partida do jogo serão analisadas como respostas aos processos } \\
\text { cognitivos eliciados no processo de Assimilação; }\end{array}$ \\
\hline Acomodação & $\begin{array}{l}\text { - As ações da quinta e última partida do jogo serão analisadas como respostas aos } \\
\text { processos cognitivos eliciados no processo de Acomodação }\end{array}$ \\
\hline \multicolumn{2}{|r|}{ Dimensão Microgenética } \\
\hline Planejamento & $\begin{array}{l}\text { - Início de uma formação sequencial com duas peças de mesma cor ou símbolo; } \\
\text { - Início estratégico na casa } 2.5 \text { aumentando as possibilidades de vitória; } \\
\text { - Reversão do jogo: defensiva seguida de ataque; } \\
\text { - Vitória de dupla possibilidade; } \\
\text { - Economia de peças que podem concluir sequencias iniciadas no bloqueio ao } \\
\text { adversário. }\end{array}$ \\
\hline Atenção & $\begin{array}{l}\text { - Início de uma formação sequencial; } \\
\text { - Bloqueio à vitória do adversário; } \\
\text { - Percepção da própria vitória. }\end{array}$ \\
\hline $\begin{array}{l}\text { Processamento } \\
\text { Sucessivo }\end{array}$ & $\begin{array}{l}\text { - Início de uma formação sequencial com duas peças de mesma cor ou símbolo; } \\
\text { - Investidas na formação sequencial em um único plano; }\end{array}$ \\
\hline
\end{tabular}


VIII Congresso Brasileiro de Informática na Educação (CBIE 2019)

Anais do XXX Simpósio Brasileiro de Informática na Educação (SBIE 2019)

\begin{tabular}{|c|c|}
\hline & - Utilização da segunda peça de mesma cor ou símbolo; \\
\hline $\begin{array}{l}\text { Processamento } \\
\text { Simultâneo }\end{array}$ & $\begin{array}{l}\text { - Utilização de mais de um plano na segunda jogada; } \\
\text { - Bloqueio à vitória do adversário envolvendo os três planos; } \\
\text { - Percepção da própria vitória envolvendo os três planos; } \\
\text { - Vitória na diagonal envolvendo os três planos. }\end{array}$ \\
\hline $\begin{array}{l}\text { Análise de } \\
\text { Pressupostos }\end{array}$ & $\begin{array}{l}\text { - Mesmo jogador que inicia as partidas por mais de três vezes seguidas, } \\
\text { independentemente de quem ganhou ou não a partida anterior, pressupôs que quem } \\
\text { inicia sempre ganhará jogo. }\end{array}$ \\
\hline $\begin{array}{l}\text { Análise de } \\
\text { Ambiguidades }\end{array}$ & $\begin{array}{l}\text { - Formação sequencial de dupla possibilidade de vitória; } \\
\text { - Jogador que promove o ataque utilizando posições que formariam sequências para o } \\
\text { adversário. }\end{array}$ \\
\hline Espaços Mentais & $\begin{array}{l}\text { Atribuição à formação sequencial como forma de vitoriana primeira jogada ou falta } \\
\text { de atribuição (quando o jogo empata, ou seja, quando termina em Velha). }\end{array}$ \\
\hline \multicolumn{2}{|r|}{ Análise Psicomotora } \\
\hline Praxia Fina & $\begin{array}{l}\text { - Velocidade e precisão no manuseio com as peças, posicionamento no tabuleiro sem } \\
\text { esbarrar nas demais e ausência de quedas. }\end{array}$ \\
\hline $\begin{array}{l}\text { Observação do } \\
\text { Tônus }\end{array}$ & $\begin{array}{l}\text { - Rápida ação concebida após preensão estática e reflexiva das peças seguida de } \\
\text { algum movimento detectável; } \\
\text { - Troca vertiginosa das peças antes da jogada, após preensão estática detectável nas } \\
\text { mesmas. }\end{array}$ \\
\hline
\end{tabular}

\subsection{Experimentação do Modelo com Simulação Manual do Protótipo}

A proposta de concretização do Hash $3 D$ envolve uma estrutura de alumínio que sustentará os três andares do tabuleiro tridimensional. Suas vinte e sete casas serão alimentadas com um circuito montado com divisores de tensão resistivos, onde cada casa estará conectada a uma porta analógica de um microcontrolador Arduino, com a ajuda de um multiplexador de 16 canais para expansão das mesmas. Dessa forma será possível identificar qual é a peça alocada em cada casa do tabuleiro uma vez que cada uma delas conterá um resistor de diferente valor ôhmico. Quando a peça for posicionada em determinada casa, o circuito será fechado por meio do contato de finas barras de cobre existentes no fundo das peças e nas casas do tabuleiro e o Arduino detectará o sinal e o valor da corrente identificando-a. A movimentação das peças será observada de forma inversa, ou seja, cada jogador iniciará a partida com suas peças organizadas em seus tabuleiros individuais e quando as mesmas forem retiradas para a jogada, o Arduino detectará a interrupção desta corrente. Os dados obtidos pelo Arduino serão enviados a um servidor local ou remoto para análise fina programada em Python.

Para testar a funcionalidade do Modelo uma versão não computadorizada foi utilizada com dez alunos voluntários de turmas do $6^{\circ}$ ao $9^{\circ}$ ano de Escolaridade de uma 
VIII Congresso Brasileiro de Informática na Educação (CBIE 2019)

Anais do XXX Simpósio Brasileiro de Informática na Educação (SBIE 2019)

Escola Pública situada no interior do Estado do Rio de Janeiro, onde os dados como o tempo de latência, o tempo de alocação das peças no tabuleiro, as peças, as casas de destino e a pontuação conforme os crivos foram coletados a partir da filmagem das partidas jogadas por cada dupla, para preenchimento de uma planilha esquematizada para este fim. $\mathrm{O}$ experimento aconteceu durante o horário de uma aula extracurricular de robótica que acontece, semanalmente, no contra turno. Seis dos alunos estão em turmas regulares, com a idade adequada a sua série e assíduos nessas aulas extracurriculares; os demais alunos pertencem a um Programa de Correção de Fluxo, o qual compreende o $6^{\circ}$ e $07^{\circ}$ ano concomitantemente e recebe estudantes com baixo rendimento escolar e com discrepância entre a idade adequada e a série atual devido às recorrentes reprovações.

Como resultado, pôde-se observar que os quatro alunos pertencentes ao Programa de Correção de Fluxo levaram mais tempo para entender o objetivo da formação sequencial, onde apenas o Aluno 7, que associou rapidamente o Hash $3 D$ ao Jogo da Velha tradicional, teve um desempenho mais próximo dos alunos das turmas regulares. Também apresentaram maior limitação na exploração de jogadas que combinassem os três andares do tabuleiro, ou seja, maior limitação no Processamento Simultâneo, onde novamente, o Aluno 7 se destacou, conforme demonstrado nos gráficos.
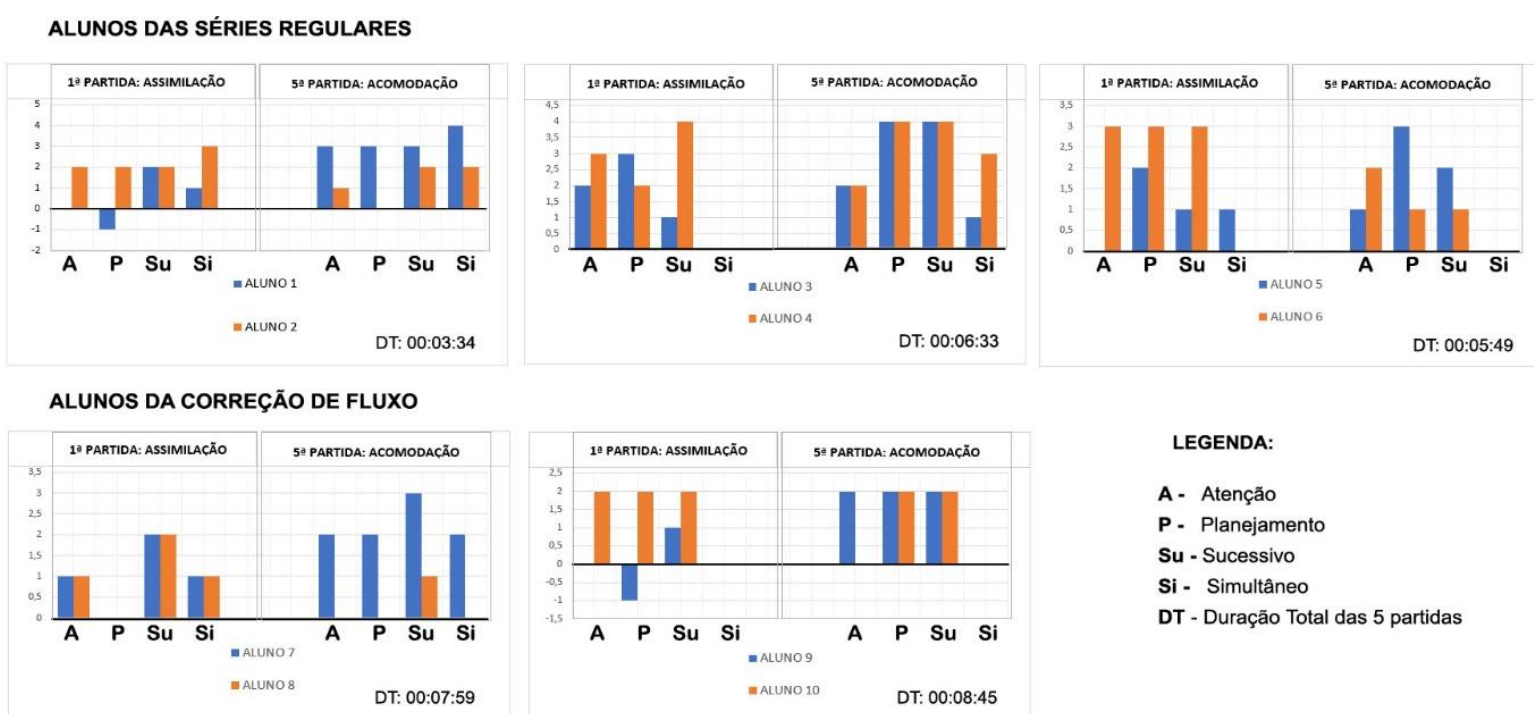

LEGENDA:

A - Atenção

P. Planejamento

Su - Sucessivo

Si - Simultâneo

DT - Duração Total das 5 partidas

Figura 5. Gráficos das jogadas

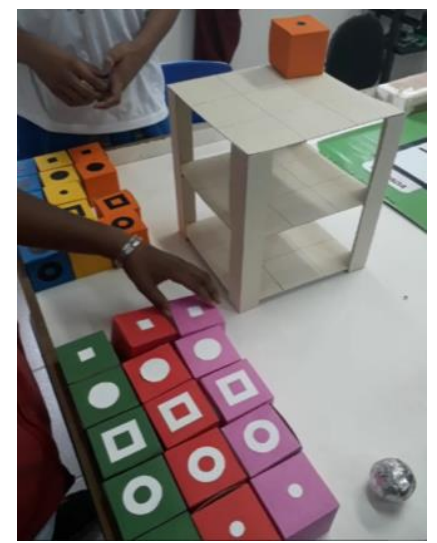

Figura 6. Aplicação do teste 
VIII Congresso Brasileiro de Informática na Educação (CBIE 2019)

Anais do XXX Simpósio Brasileiro de Informática na Educação (SBIE 2019)

\section{Conclusão}

Conclui-se que esse trabalho é uma proposta lúdica, manifestada de forma positiva por todos os alunos que participaram, dotada de um nível de interatividade cujo design remete aos brinquedos tradicionais, ao mesmo tempo que dispõe de tecnologia e inovação no que diz respeito à observação de fenômenos cognitivos. Presume-se que a literatura escolhida como fundamentação teórica seja qualitativamente coerente na análise das atitudes tomadas durante as partidas do jogo, possibilitando a mensuração dos processos de Planejamento, Atenção, Processamento Sucessivo e Processamento Simultâneo que acontecem implicitamente no sujeito, diante de desafios inéditos, durante os momentos de Assimilação e Acomodação formadores da cognição.

Espera-se que o protótipo seja construído e testado com novos alunos voluntários para confirmar se os resultados serão coletados de uma forma mais eficiente e menos exaustiva do que foi feito manualmente. Espera-se também, que esses dados sejam transmitidos diretamente do JIT para uma nuvem, possibilitando o acesso remoto e promovendo a integração do atual conceito IoT ao trabalho.

\section{Referências}

Fonseca, V. (2012) "Manual de observação psicomotora: significação psiconeurológica dos fatores psicomotores". 2.ed. Wak Editora, Rio de Janeiro.

Gluz, J. C. et. al. (2018) “Ambiente Virtual Tangível para Integração Sensorial no Ensino de Ciências numa Perspectiva Inclusiva”. In Anais do SBIE 2018, pages 545-554.

Inhelder, B. et. al. (1996) "O Desenrolar das descobertas da criança: pesquisa acerca das microgêneses cognitivas”. Trad. Eunice Gruman. Artes Médicas, Porto Alegre.

Jordà, S. et. al. (2005) "The reacTable* A Tangible Tabletop Musical Instrument and Collaborative Workbench". Pompeu Fabra University, Barcelona. https://www.researchgate.net/publication/247929547_The_reacTable_a_tangible_tablet op_musical_instrument_and_collaborative_workbench.html, December.

Luria, A. R. (1966) "Human Brain and Psychological Processes". 1 a . ed. Harper \& Row, Nova York.

Marques, C. V. M. (2017) EICA - Estruturas Internas Cognitivas Aprendentes: Um Modelo Neuro-Computacional aplicado à instância psíquica do Sistema Pessoa em Espaços Dimensionais. Tese de Doutorado. COPPE/ UFRJ, Rio de Janeiro.

Marques, C. V. M.; Calil, E.; Brasil, G. (2015) “Game Inteligente: conceito e aplicação”. In Anais do Seminário de Jogos Eletrônicos, Educação e Comunicação, v. 1, n. 1, pages $162-171$.

Mennucci, S. (1934) “A Crise Brasileira da Educação”. 2.ed. Piratininga, São Paulo.

Oliveira, G. de C. (2001) "Psicomotricidade: educação e reeducação num enfoque psicopedagógico". 5.ed. Vozes, Petrópolis.

Piaget, J. W. F. (1976) “A Equilibração das Estruturas Cognitivas: Problema Central do Desenvolvimento". Zahar Editores, Rio de Janeiro. 